$$
\text { CONF-870570-8 }
$$

UCRL-96416

PREPRINT

\title{
Localized Electron-Cyclotron Heating and Current \\ Drive in the TIBER-II Reactor Study
}

\author{
G. R, Smith \\ B. G. Logan \\ LLHL \\ A. H. Kritz \\ Hunter College/CUNY
}

This paper was prepared for submittal to

Seventh Topical Conference on Applications

Radio-frenuency Poker to Plasmas

Kissimee, Florida

lay 4-6, 1987

May 1, 1987

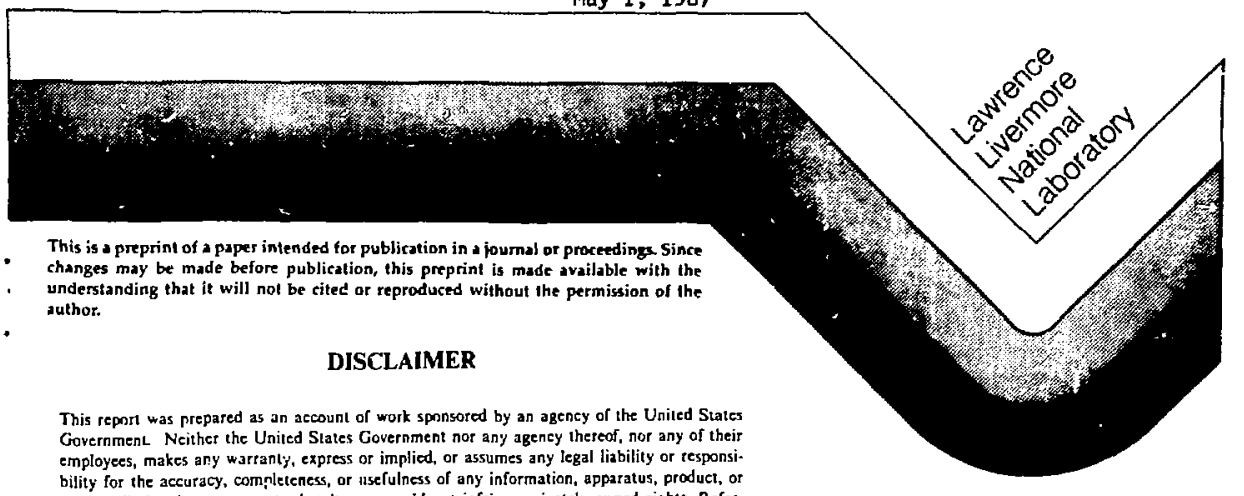
prosess disclosed, ar ecpresents that ils use would sot inftinge privalely owned rights. Refer. ence herein to any specific commercial produci, prosess, at service by trade name, trademark. manufaeturer, of otherwise dues not necessar jly constitute or imply its endorsement, recommendation, or favoring by the United States Government or any agency thereof. The views and opinions of authors expressed herein do nol necessarily state or reflect those of the Unital Stater Gat. ernment or any agency thereof. 


\title{
Localized Electron-Cyclotron Heating and Current Drive in the TIBER-II Reactor Study"
}

Gary R. Smith and B. G. Logan

Lawrence Livermore National Laboratory

University of California, Livermore, CA 94550

UCRI,-96416

A. H. Kritz'

DE87 009852

Hunter College/CUNY, New York, NY 1002]

\begin{abstract}
A scenario is shown for launching $10 \mathrm{MW}$ of $450 \mathrm{GHz}$ extraordinary-mode electron-cyciotron waves into a TIBER-II equilibrium. Localized, high-efficiency current drive near but outside the $q=2$ surface causes substantial reduction in the current gradients that may play a role in major disruptions and anomalous transport. The same launch geometry shows promise for heating the plasma core during startup.
\end{abstract}

\section{INTRODUCTION}

In a high-temperature tokamak reactor, broad electron-cyclotron resonances lead to constraints on current-drive efficiency at the psak $T_{e}$ achieved during burn in the plasma core. ${ }^{1}$ At lower $T_{e}$, however, the injection of electroncyclotron power can serve two useful purposes. First, during plasma startup, localized heating of the core can help initiate the burn. Second, to minimize transport and suppress wsruptions, one can control the radial profiles of $T_{e}$ and plasma current near and outside of the $q=2$ surface. This paper reports initial work towards these goals.

\section{LOCALIZED, HIGH-EFFICIENCY CURRENT DRIVE}

High-efficiency current drive by electron-cyclotron waves is achieved by selectively heating high-energy electrons that have parallel velocity of one sign. The relativistic, wave-particle resonance condition is satisfied for such electrons if the parallel index of refraction $\left|N_{n}\right|=\mathcal{O}(1)$ and if $\ell \Omega / \omega<1$, where $\ell$ is the harmonic number, $\Omega$ is the cyclotron frequency, and $\omega$ is the wave frequency. Typical values for these parameters are $\left|N_{\mathrm{l}}\right|=0.6$ and $\ell \Omega / \omega=0.9$.

Localization of power deposition and current drive to a small range of flux surfaces is accomplished by choice of the launch geometry and of the polarization. Wave absorption must be strong and occur where propagation

- This work was performed under the auspices of the U.S. Department of Energy by Lawrence Livermore National Laboratory under contract No. W-7405-Eng-48.

1 Supported by USDoE under Contr. DE-FG02-84-ER5-3187. 


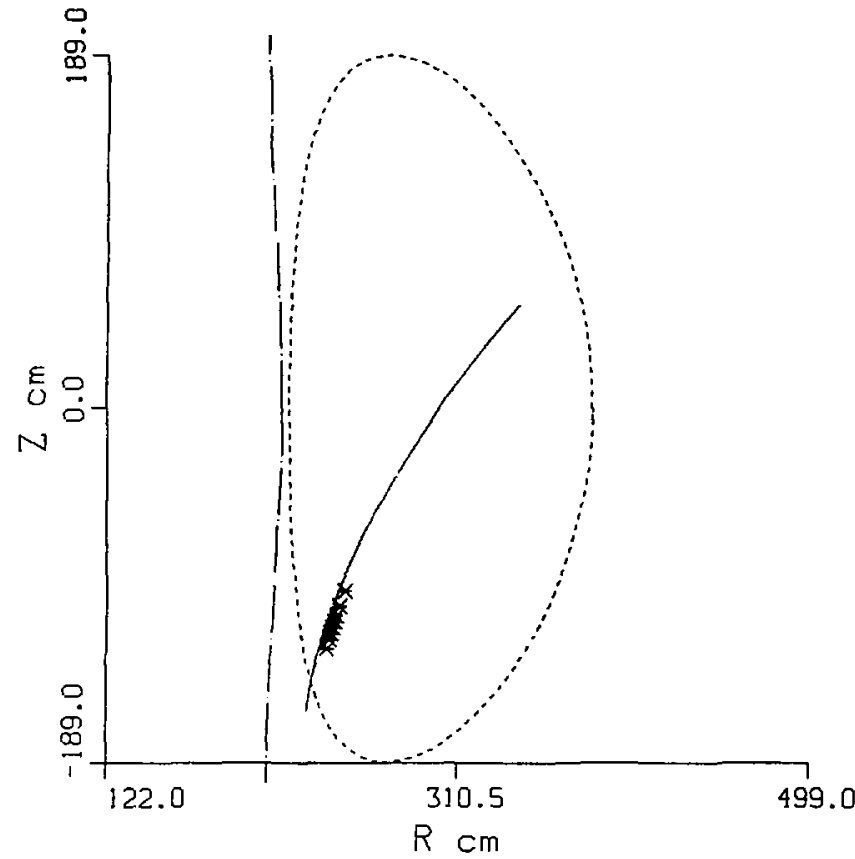

Fig. 1. Polojdal projection of a ray trajectory that deposits pover and drives current out side the $q=\mathbf{2}$ surface in a TIBER-II equilibrium. The dashed curve is the $\bar{\psi}=0.96$ fiux contour. The chain-dot curve is the second-harmonic cyclot ron resonance. The asterisks indicate the loration of wave absorption.

is at a relatively small angle with respect to the flux surfaces. For any harmonic $l$, the extraordinary mode has the stronger absorption.

An attractive launcl geometry for the TIBER-II study is illustrated in Fig. 1. The launch location is just ontside the separatrix of the diverted equilibrium. Extraordinary-mode power at $450 \mathrm{GHz}$ is launched at polar angle $\theta=50^{\circ}$ and at azimuthal angle $\phi=285^{\circ}$ in a cylindrical coor linate system coaxial with the tokamak axis of synmetry. Power absorption is linited to the region outside the $q=2$ flux surface and amounts to $99 \%$ of the incident power. Second-harmonic cyclotron resonance absorbs the waves in a region where magnetic-field and plasma parameters have the values $B \approx \pi .2 \mathrm{~T}$, 
$n \lesssim 0.46 \times 10^{20} \mathrm{~m}^{-3}$, and $T_{\mathrm{e}} \leqslant 10 \mathrm{keV}$. Third-harmonic absorption is not shown here but becomes significant farther along the ray, just after the second-hermonic absorption decreases; no power reaches the center of the plasma. These results are calculated with the TORAY ray-tracing code. ${ }^{2,3}$ Absorption is calculated for a Maxwellian electron distribution function.

Second-harmonic extraordinary-mode absorption is used here, but an alternative scenario for localized power deposition and current drive utilizes the ordinary-mode polarization and the fundamental cyclotron resonance with $\omega \approx 225 \mathrm{GHz}$. With either scenario, for accurate results the wave damping must include the warm-plasma effects on wave polarization. In this paper, coldplasma polarization is used, and the results may be quantitatively inaccurate but are probably qualitatively correct.

The calculation of current-drive efficiency presented in Ref. 4 is used here to obtain the current driven in conjunction with second-harmonic power absorption. This calculation includes the effects of the relativistic resonance condition and of trapped electrons, both of which can alter current-drive efficiency significantly.

Figure 2 shows the effect of $10 \mathrm{MW}$ of electron-cyclotron power on the currest flowing in the TIBER-Il plasma. The plots show the toroidal current enclosed within each flux surface, where the surfaces are parametrized by the normalized poloidal flux $\bar{\psi}=\left(\psi-\psi_{\text {axis }}\right) /\left(\psi_{\text {eder }}-\psi_{\text {axis }}\right)$. The integrated equilibrium current $I_{p}$ (dashed curve) is characterized for $0<\bar{\psi}<0.6$ by nearly corstant slope, which implies that $d l_{p} / d \bar{\psi}$ is almost flat. For $\bar{\psi}>0.6$ and, in particular, near the $q=2$ surface at $\bar{\psi}=0.73, d I_{\mathrm{p}} / d \bar{\psi}$ decreases with increasing $\bar{\psi}$, indicating a gradient in the current profile that may be associated with major disruptions. The solid curve, which is calculated from the sum of the equilibrium and the driven curvents, maintains the nearly constznt slope to larger $\tilde{\psi}$. With electron-cyciotron current drive, therefore, the current gradient is reduced near the $q=-2$ surface, which may help to control disruptions and minimize transport.

\section{HEATING DURING STARTUP}

Ideally, the chosen launch geometry should also serve to heat the plasma core during st art up and help to initiate the burn. Typical values at the magnetic axis for density and temperature are $\bar{n}=5 \times 10^{20} \mathrm{~m}^{-3}$ and $\dot{T}_{\mathrm{e}}=8 \mathrm{keV}$. The ray trajectory is similar to that showr. in Fig. 1, because refraction is small both during startup and during steady state. Second-harmonic absorption is much reduced from that shown in Fig. 1, because the cooler plasma has very few electrons at the $\ell=2$ resonance. The third-harmonic resonance occurs close to the magnetic axis, and localized absorption may occur there due to the strong $T_{e}^{2}$ dependence of third-harmonic damping. Future work will examine these questions quantitatively. 


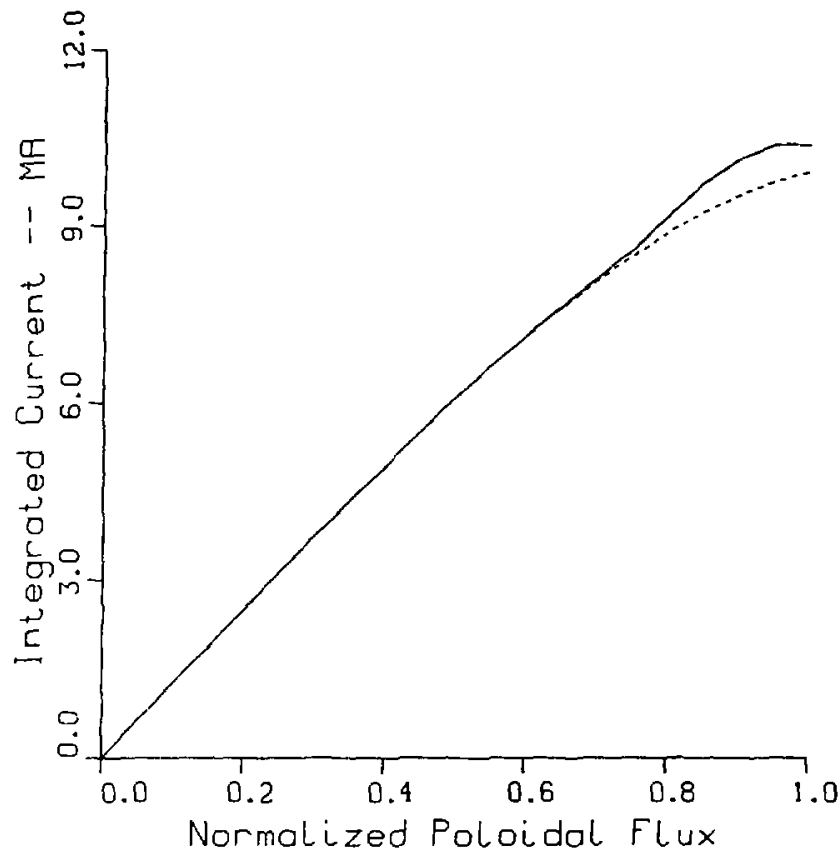

Fig. 2. Enclosed current as a function of nornalized poloidal thux $\bar{q}$. The solid curve differs from the dashed curve due to $10 \mathrm{MW}$ of second-harmonic $\mathrm{X}$-mode power.

\section{REFERENCES}

' G. R. Smith, R. H. Cohen, and T. K. Mau, LLNL Report No. UCRL-96364. submitted to Phys. Fluids, March 1987.

7. A. H. Kritz, H. Hsuan, R. C. Goldfinger, and D. B. Batchelor, in Proc. 3rd Joint Varenna-Grenoble International Symp. on Heating in Toroidal Plasmas. (Commission of the European Communities, Brussels, 1982), Vol. II, p. 707.

3 G. R. Smith, W. M. Nevins, R. H. Cohen, and A. H. hritz, Bull. Amer. Phys. Soc. 31, 1516 (1986),

4 R. H. Cohen, "Effect of Trapped Electrons on Current Drive," LLNL Report No. UCRL-95813 Rev. 1, to be published in Phys. Fluids, 1987. 